\title{
LA PROPAGANDA, EL ENTRETENIMIENTO Y LA EDUCACIÓN EN LOS ESPACIOS INFANTILES DE LA RADIODIFUSIÓN DE LAS ISLAS CANARIAS DURANTE EL FRANQUISMO, 1939-1975
}

\author{
Propaganda, entertainment and education on children's \\ programmes in the radio broadcast of the Canary Islands \\ during the Franco's regime, 1939-1975
}

\section{Julio Antonio Yanes Mesa*}

Fecha de recepción: 29/03/2016 • Fecha de aceptación: 27/05/2016

Resumen. La programación infantil de la radiodifusión canaria no fue ajena a la propaganda que, en los ámbitos cultural, educativo e, incluso, lúdico, dirigieron los medios de comunicación a la infancia y la adolescencia en el franquismo. No obstante, desde el punto de vista de la autoría de los espacios, ese afán proselitista se circunscribió a los grabados en cinta magnetofónica que llegaban de la península y a los que elaboraban los militantes del régimen en las islas, toda vez que los producidos por el personal de las propias emisoras giraron, cada vez más, en torno a contenidos despolitizados y, en el caso de los educativos, al uso de metodologías que podríamos considerar antagónicas a las propugnadas por los ideólogos de la dictadura. Razones contextuales como la lejanía de Madrid, el liberalismo de la idiosincrasia insular y la incompatibilidad de las tesis autárquicas franquistas con la tradicional apertura al exterior de la economía isleña, hacen explicable la presencia de tales disonancias en un espacio tan periférico como el archipiélago. Esas mismas razones son las que nos permiten comprender la paradoja de que los logros más audaces en el campo educativo tuvieran como protagonistas a las emisoras más marginales $\mathrm{y}$, por lo tanto, menos asediadas por la censura de la época.

Palabras clave: Franquismo. Propaganda. Enseñanzas radiofónicas. Periferia. Islas Canarias.

\footnotetext{
* Departamento de Ciencias de la Comunicación y Trabajo Social. Facultad de Ciencias Políticas, Sociales y de la Comunicación. Universidad de La Laguna. Edificio Pirámide. 38071 La Laguna . Santa Cruz de Tenerife. España. jayanes@ull.edu.es
}

Cómo citar este artículo: Yanes Mesa, Julio Antonio. «La propaganda, el entretenimiento y la educación en los espacios infantiles de la radiodifusión de las Islas Canarias durante el franquismo, 1939-1975», Historia y Memoria de la Educación, 4 (2016): 371-392. 
Abstract: Children's programmes in the Canary Islands' radio broadcasting were not isolated from the propaganda used by the media towards children and adolescents in cultural, educational and even ludic spheres during Franco's regime. However, with respect to the authorship of the programmes, the government's proselytizing zeal was limited to the tape-recorded broadcasts brought from the Peninsula and those produced by the regime's local activists; as for transmissions produced by local broadcasters, they increasingly revolved around apolitical contents, and in the case of the educational programs, contents were focused on the use of methodologies we can consider antagonistic to the propaganda promulgated by the dictatorship's ideologists. Contextual reasons such as the distance from Madrid, the liberalism inherent in the insular idiosyncrasy and the incompatibility of the autocratic thesis of Franco's regime with the traditional openness to foreign trade in the islands help to explain the appearance of these discordances in such an outlying region as the Archipelago. These same reasons allow us to understand the paradox of the most innovative achievements in the educational field being carried out by broadcasts with an audience that was considerably smaller and, therefore, less prone to be under the scrutiny of the censors at the time.

Keywords. Francoism. Propaganda. Radio broadcasting teachings. Outlying area. Canary Islands.

\section{PLANTEAMIENTO}

Aunque la propaganda franquista prestó especial atención a la población infantil y juvenil, la necesidad de atraer audiencia atemperó, en el caso del mensaje emitido a través de la radiodifusión, el ímpetu de tales campañas. Esta circunstancia se hizo particularmente notoria en el micro-espacio extra-peninsular que conforman las Islas Canarias, cuyos condicionantes geográficos e históricos se sumaron a las exigencias comerciales para relajar en mayor medida aún el afán proselitista de los contenidos radiofónicos dirigidos a los segmentos más tiernos de la población. Nos referimos a la insularidad y a la lejanía de Madrid, al pragmatismo y al moderantismo que la prensa autóctona ha reflejado de la idiosincrasia insular a lo largo de la historia, ${ }^{1}$ a la tradicional apertura

\footnotetext{
${ }^{1}$ Julio Antonio Yanes Mesa, Historia del Periodismo Tinerfeño, 1758-1936. Una visión periférica de la Historia del Periodismo Español (Santa Cruz de Tenerife: Centro de la Cultura Popular Canaria, 2003), 551-556, en particular.
} 
exterior de la economía canaria ${ }^{2}$ y, en coherencia con todo ello, al unánime rechazo de las tesis autárquicas del régimen ${ }^{3}$ y a la reducidísima implantación de Falange en el archipiélago. ${ }^{4}$ A la vista del escaso predicamento del ideario franquista en las islas, hemos desarrollado la investigación a partir de la siguiente hipótesis: la programación infantil de las emisoras canarias durante la dictadura se caracterizó por la escisión existente entre los espacios de producción interna, en los que predominó el entretenimiento y la educación, y los recibidos en cinta magnetofónica de Madrid o elaborados por la militancia del partido único en el archipiélago, en los cuales primó la propaganda ideológica.

Para verificar dicha hipótesis, hemos analizado y contextualizado la programación infantil, tanto recreativa como cultural y educativa, de las emisoras de la provincia occidental del archipiélago a lo largo de aquellas casi cuatro décadas, prestando especial atención a las diferencias existentes en el afán proselitista de unos y otros espacios. Para estudiar los de producción propia, ante la falta de conservación de grabaciones, hemos recurrido a las fuentes hemerográficas, ${ }^{5}$ archivísticas y orales, mientras las referencias a los producidos externamente nos las ha suministrado el estado de la cuestión que ofrece la bibliografía disponible. Del cúmulo de periódicos consultados, los más productivos han sido Diario de Avisos de Santa Cruz de La Palma (1890-1976), Gaceta de Tenerife (1910-1939), Hoy (1932-1936), La Tarde (1927-1981) y la revista especializada Radio Tenerife (1935-1936); todos editados en la provincia de Santa Cruz de Tenerife. En cuanto a los centros documentales visitados, los datos más valiosos los encontramos en el Archivo Municipal de Santa Cruz de La Palma, mientras las entrevistas más esclarecedoras han tenido como protagonistas a Eloy Díaz de la Barreda, colaborador de Radio Club

\footnotetext{
2 Antonio Manuel Macías Hernández y José Ángel Rodríguez Martín, «La economía contemporánea, 1820-1990», en Historia de Canarias, dir. Antonio de Bèthencourt Massieu (Las Palmas: Cabildo de Gran Canaria, 1995), 369-398.

3 Ricardo Alberto Guerra Palmero, Sobrevivir en Canarias (1939-1959). Racionamiento, miseria y estraperlo (Santa Cruz de Tenerife y Las Palmas de Gran Canaria: Ediciones Idea, 2006), 205-258, en particular.

4 Aarón León Álvarez, La institucionalización del franquismo en las Canarias occidentales (1936-1961) (Tesis doctoral, Universidad de La Laguna, 2015), 437-547, en particular.

5 En el caso de los datos recabados en los textos sin firmar que tanto proliferaban en los periódicos de la época, como estos eran escritos por los propios redactores, hemos preferido consignar la autoría con los términos «nota de la redacción» en lugar de «anónimo».
} 
Tenerife, el sacerdote José Siverio Pérez, jefe de programación de $\mathrm{La}$ Voz del Valle de La Orotava, Diego García Soto, técnico de Radio Juventud de Canarias, Javier Apraiz de Elorza, guionista y locutor de Radio Popular de Güimar, y el actual profesor de Psicología de la Universidad de La Laguna y, por entonces, participante de los espacios infantiles de la última emisora citada, Pedro González Leandro.

A la hora de rendir cuentas de los resultados de la investigación, hemos optado por exponer y discutir, simultáneamente, los hechos que hemos podido recuperar a partir de los datos obtenidos, siguiendo criterios cronológicos, para, al final, sintetizar las conclusiones más relevantes. La microhistoria italiana, con sus pautas sobre el estudio intensivo e indiciario de la documentación recabada y el diálogo micro y macro-espacial entre los ámbitos insular y estatal, ${ }^{6}$ nos ha orientado metodológicamente para detectar las especificidades insulares y, así, comprobar el grado de confirmación de nuestras conjeturas. En el proceso investigador, la diversa procedencia de los datos utilizados nos fue enormemente útil, no sólo para cribar la información obtenida a través del cruce de unos y otros, sino también para corregir las limitaciones unilaterales de cada fuente a la luz de las realidades desveladas por las otras y, de este modo, dar vivacidad a los documentos de archivo y más objetividad a los textos periodísticos y a los testimonios orales. Especial mención merecen estos últimos por permitirnos acceder a fragmentos de realidad que estaban condenados a desaparecer con el fallecimiento de las respectivas personas informantes, toda vez que no dejaron huella en ningún registro documental, los cuales han sido fundamentales para llevar a buen puerto la investigación.

\section{LA ORIENTACIÓN LAICA Y CULTURAL DE LOS AÑOS DE LA REPÚBLICA, 1934-1936}

Mientras la pionera de las emisoras de la zona occidental de las Islas Canarias, Radio Club Tenerife, estuvo emitiendo en onda corta con un equipo alegal, cosa que hizo entre mediados de los años veinte y mayo de 1934 , sus promotores no pusieron en antena espacios infantiles como los

\footnotetext{
${ }^{6}$ Giovanni Levi, «Sobre microhistoria», en Formas de hacer Historia, ed. Peter Burke (Madrid: Alianza Universidad, 1999), 119-142; Carlos Antonio Aguirre Rojas, Microhistoria italiana: modo de empleo (Barcelona: Montesinos, 2014).
} 
que por entonces ofrecían Unión Radio y las demás estaciones de onda media de Madrid y Barcelona. ${ }^{7}$ Los reducidos horarios de emisión, a primeras horas de la noche, y el exiguo número de aparatos receptores que había en el archipiélago, hacían del elitismo y la solemnidad los rasgos distintivos de las ondas hertzianas isleñas, cuyos contenidos tenían como destinatarios a las élites sociales de la población adulta. Por entonces, el protagonismo infantil se reducía a la ocasional intervención de algún pequeño o pequeña ante el micrófono con el exclusivo propósito de introducir, con la frescura e inocencia propias de la edad, ciertas dosis de distensión en los solemnes espacios culturales de la época.

Sería en plena República, tras la inauguración del equipo de onda media el 13 de mayo de $1934,{ }^{8}$ cuando aparecieron, aunque esporádicamente, los primeros programas dirigidos al segmento más tierno de la audiencia. Los protagonistas eran los niños y niñas curtidos previamente, tanto en el teatro Guimerá de la ciudad de Santa Cruz como en los festejos populares, en la recitación, el cante, el manejo de algún instrumento musical o, simplemente, la lectura en voz alta de textos. A propósito de uno de estos espacios, la prensa hablaba de una "precoz pianista», de otra "niña muy simpática, con una desenvoltura impropia de su edad», de un niño que había disertado sobre un tema tan sesudo como «los insectos», de otra pequeña que destacaba por la "gracia, simpatía y estilo» que ponía en todo lo que hacía, y de la «artista infantil» Marinita Núñez, ${ }^{9}$ a la que catalogaba como "émula de la actriz, cantante y recitadora» argentina Berta Singerman (1902-1998). Los versos que en aquella ocasión recitó la propia Marinita Núñez, nos permiten entrever el tono de los contenidos que se emitían en aquellas veladas:

Tengo enferma mi muñeca, / que se llama Colombina. / Mi muñeca en muy inquieta. / Es morena, y es divina. / ¿Por qué sufres

\footnotetext{
${ }^{7}$ Armand Balsebre, Historia de la Radio en España (1939-1985), tomo II (Madrid: Cátedra, 2001), 158-160; Silvia Espinosa Mirabet y Lidia Borrero, «Los programas infantiles de radio en Cataluña: una aproximación cronológica a la tipología de programas de radio para niños», Quaderns del CAC, XVIII (41), (2015), 58-59.

8 Julio Antonio Yanes Mesa, Los orígenes de la radiodifusión en Canarias. "Radio Club Tenerife», 19341939 (Santa Cruz de Tenerife: Baile del Sol, 2010), 39-132.

${ }_{9}$ Hija del rapsoda Enrique Núñez Marrero, uno de los referentes de la radiodifusión canaria del primer franquismo en el arte de la recitación, y hermana de la locutora Candelaria (Cayaya) Núñez, cuya voz era de las más populares en la época.
} 
corazón, / sabiendo cómo te quiero? / Me mira con gran pasión; / la beso, mas no lo inquiero. / Siempre me miras así. / ¿Me guardas algún secreto? / Dímelo tan solo a mí, / mi corazón es discreto / ¡Ya comprendo tu dolor! / Quieres volver al bazar. / Allí quedó Pierrot, / y con él querrás jugar. / De tu ilusión me hago eco. / ¿Deseas la libertad? / ¡Sea!, ve con tu muñeco. / De mí, ¿quién tendrá piedad. ${ }^{10}$

Estos programas tenían como referencia a los culturales de los adultos, cuya estructura literario-musical reproducían al pie de la letra con la salvedad de que, ahora, "los mismos chiquitines son los que hablan, recitan versos, cantan y narran cuentecillos». ${ }^{11}$ Paralelamente, dentro de la corriente que en la II República introdujo a la prensa ${ }^{12}$ y a la radio ${ }^{13}$ en los centros educativos españoles como recurso pedagógico, a imitación de lo que sucedía en los países occidentales más desarrollados, Radio Club Tenerife ofrecía el micrófono a los directores de los colegios para que los profesores, con sus propios alumnos, pusieran en antena espacios de carácter educativo. La propuesta se consolidó con periodicidad bisemanal a partir del 11 de abril de 1935, cuando tales eventos empezaron a salir al aire los domingos y jueves, normalmente, entre las 13:15 y las 14:15 horas. Las palabras con las que el director artístico de la emisora, Manuel Ramos Vela, anunció la novedad ante el micrófono, remarcan el modelo de servicio público que siempre tuvieron en mente los gestores de la radiodifusión isleña en la II República:

Hoy, después de muchísimos contratiempos, iniciamos las emisiones infantiles que este (SIC) radio club organiza en honor de nuestros pequeños oyentes. El objeto de ellas no es solamente que el niño oiga; tiene un fin más importante y es que el niño inteligente, y con previa preparación, pueda mostrar ante el micrófono las facultades de su talento y cultura, aprendiendo, a

\footnotetext{
${ }^{10}$ Gustavo García Fernández, «Ilusión», revista mensual Radio Tenerife (Santa Cruz de Tenerife), mayo de 1935.

11 Nota de la redacción, diario Hoy (Santa Cruz de Tenerife), 31 de mayo de 1935, 2.

12 Julio Antonio Yanes Mesa, «La prensa escolar en España (1868-2003): perspectiva histórica y panorama actual», en Prensa y Periodismo Especializado, II, coords. Carlos Sanz Establés, Joaquín Sotelo González y Ángel Luis Rubio Moraga (Guadalajara: Universidad Complutense de Madrid y Asociación de la Prensa de Guadalajara, 2004), 189-200.

${ }^{13}$ Espinosa Mirabet y Borrero, «Los programas infantiles de radio en Cataluña ...», 58.
} 
la vez, a desenvolverse con facilidad. Y al mismo tiempo, que al que escucha le sirva como una clase más que recibe, que siendo, como es, oída con atención no igualada, no pueda olvidarse fácilmente, ya que puso en ella toda su imaginación y sentidos. [...] Queremos hacer un llamamiento a todos los centros de enseñanza de Tenerife para ofrecer este micrófono a cuantos señores profesores deseen presentar a sus alumnos en estas ya repetidas emisiones infantiles, así como a los particulares que gusten. Y ahora, niñas y niños radioyentes, poned atención a los hermanitos y compañeros que en estos momentos vais a escuchar, que ello sea un estímulo para todos, como no podemos dudar, y esperamos en próximas emisiones la simpática y valiosa cooperación de cuantos queráis; teniendo en cuenta que, estudiando con voluntad y cariño, podréis hablar, cantar y ejecutar ante el micrófono de Radio Club Tenerife, que es de todos. ${ }^{14}$

Con el decurso de los meses, el reducido número de centros educativos de la época propició el establecimiento de una especie de turno, que a los escolares más destacados, aquellos que se ponían recurrentemente delante del micrófono, les permitió familiarizarse con el medio. En el listado figuraban desde el elitista Colegio Alemán, cuyo alumnado alternaba el uso de la lengua germana con la española, ${ }^{15}$ a los tres grupos escolares de enseñanza pública recién inaugurados dentro de la política educativa de la II República, pasando por colectivos sectoriales como la «sección artística de los Estudiantes católicos». ${ }^{16}$ En las grandes ocasiones, se celebraban emisiones extraordinarias como la que, el Día de Reyes de 1936, corrió a cargo del Colegio del Corazón de Jesús a partir de las 14:00 horas. En esta ocasión, el presentador fue un alumno, quien dio paso a las palabras preliminares de su director, Rafael Gaviño Del Bosque, ${ }^{17}$ y a la actuación

\footnotetext{
${ }^{14}$ Manuel Ramos Vela, «Emisiones infantiles», mensuario Radio Tenerife, (Santa Cruz de Tenerife), mayo de 1935; nota de la redacción, diario Hoy (Santa Cruz de Tenerife), 11 de abril de 1935, 1.

15 Nota de la redacción «Una emisión por los alumnos del Colegio Alemán», mensuario Radio Tenerife, (Santa Cruz de Tenerife), julio de 1935.

${ }^{16}$ Notas de la redacción, diario Gaceta de Tenerife (Santa Cruz de Tenerife), 11 de julio y 9 de noviembre de 1935, 3 y 4, respectivamente.

${ }^{17}$ Rafael Gaviño del Bosque combinaba su vocación pedagógica con la periodística, dado que colaboraba esporádicamente con temas educativos en la prensa tinerfeña, lo que, a su vez, ilustra la cercanía que en los años de la República tenía la radiodifusión y, en general, el periodismo con la educación.
} 
de sus compañeros, uno de los cuales, Gustavo Castellano Gámez, haría luego de la radio su profesión. ${ }^{18} \mathrm{El}$ programa terminó con el típico sorteo de juguetes donados por las firmas comerciales más diversas de la ciudad entre los hijos de los socios de Radio Club Tenerife. ${ }^{19}$

\section{EL GIRO FASCISTA EN LA DÉCADA TRÁGICA, 1936-1945}

La orientación laica, cultural y educativa desapareció súbitamente de las ondas hertzianas isleñas el 18 de julio de 1936, cuando desde el micrófono de la propia emisora se dio lectura al bando de los sublevados contra el gobierno de la República que desató la guerra civil. A renglón seguido, con el uso adicional de varios equipos de onda corta, incluido el de 20 kilovatios de la Compañía Nacional Telefónica, Radio Club Tenerife se convirtió en la plataforma de retransmisión internacional más potente del mensaje de los rebeldes. ${ }^{20}$ La programación infantil no reapareció hasta un año más tarde, en el primer aniversario de la insurrección militar, cuando los espacios propagandísticos de Radio Nacional de España en Burgos que llegaban por onda corta al archipiélago incorporaron el recién creado «Ondas animadas». Puesto en antena los domingos al mediodía con una duración de 15 minutos, la temática se reducía a biografías de héroes y santos, gestas históricas del ejército español e, incluso, un "parte de guerra infantil», ${ }^{21}$ al objeto de inculcar en los niños y niñas, en estas con un resultado aún más devastador, ${ }^{22}$ los valores del embrionario régimen.

\footnotetext{
${ }_{18}$ Gustavo Castellano Gámez entraría inmediatamente después de la guerra civil, siendo aún muy joven, en Radio Club Tenerife para hacerse cargo, bajo el seudónimo Sportman, de los deportes, cometido que luego alternó con sus colaboraciones en la prensa de la isla. Julio Antonio Yanes Mesa, La radiodifusión privada en Canarias durante el franquismo. Radio Club Tenerife, 1939-1975 (Islas Canarias: Ediciones Densura 2012), 91, 104, 172, 173, 175, 180 y 195.

19 Notas de la redacción, diario Hoy (Santa Cruz de Tenerife), 4 y 5 de enero de 1936, 2 y 8, respectivamente.

20 Julio Antonio Yanes Mesa, «La propaganda radiofònica de l’Espanya nacional a Canàries Durant la Guerra Civil, 1936-1939», Anàlisi. Quaderns de comunicació i cultura, 41 (2011), 101-116.

${ }^{21}$ Salvador Gómez García, «Adoctrinando el futuro: las emisiones infantiles y juveniles de Radio Nacional de España durante el primer franquismo», ZER. Komunikazio ikasketen aldizkaria, 30 (2011), 137-141.

${ }_{22}$ Montserrat Huguet Santos, «Memoria del primer franquismo. Mujeres, niños y cuentos de infancia», en Donne e bambini, ed. Antonella Cagnolati (Italia: Università degli Studi de Foggia, 2013), consultado el 15 de marzo de 2015, URL: www.empleo.gob.es.
} 
El cese de la lucha fratricida no significó que Radio Club Tenerife dejara de ser altavoz propagandístico de Radio Nacional de España en el exterior, labor que, incluso, acentuó desde el inmediato estallido de la II Guerra Mundial. Ello tampoco impidió que, a los dos meses escasos, la emisora tinerfeña pusiera en antena un programa infantil propio cara al público, los jueves a las 18:30 horas, con un tono de entretenimiento. El Hombre Bueno, el Príncipe Infantil y El Abuelito ${ }^{23}$ fueron los sucesivos personajes de ficción sobre los que basculó el espacio, a los cuales dio voz el polifacético locutor Juan Antonio Torres Romero. Luego, con carácter extraordinario, retornaron los programas culturales de la República en los que los niños y niñas, a imitación de lo que hacían los adultos, recitaban poemas, leían textos, cantaban o ejecutaban piezas musicales con instrumentos diversos, aunque ahora sobre el sustrato patriótico y religioso que envolvía todo el quehacer de la época. Con las mismas limitaciones, también se convocaron concursos de cuentos cortos sobre «educación, hechos históricos de la provincia, enseñanza (sic), etc.», ${ }^{24}$ que eran leídos en el programa infantil citado, y otros sobre actividades plásticas, uno de «dibujos y pequeñas esculturas sobre nuestra región» ${ }^{25}$ para los adolescentes, y otro sobre pintura y dibujo a «lápiz, pluma, carboncillo, tinta china, acuarela, creyones, ${ }^{26}$ etc. ${ }^{27}$ para los más pequeños, con los cuales se organizaban exposiciones en los bajos de la propia emisora.

Por consiguiente, en el primer tramo de la II Guerra Mundial, Radio Club Tenerife simultaneó la retransmisión del espacio infantil de producción externa «Ondas animadas», que estaba en antena los sábados por la mañana con una carga propagandística potenciada desde $1942,{ }^{28}$ con la

\footnotetext{
${ }^{23}$ Referencias a los tres personajes en diversos textos periodísticos sin especificar autorías aparecen, sucesivamente, en estos diarios de Santa Cruz de Tenerife: La Tarde, 29 de junio de 1939, 4; El Día, 13 de mayo de 1941, 1; y La Tarde 14 de noviembre de 1941, 5 de enero de 1942 y 13 de mayo de 1943, 4 en los tres números.

24 Bases del concurso, diario La Tarde (Santa Cruz de Tenerife), 8 de julio de 1941, 2.

${ }^{25}$ Bases del concurso, diario La Tarde (Santa Cruz de Tenerife), 15 de diciembre de 1943, 3.

${ }^{26}$ El término «creyón», que proviene del francés «crayon», se usa en Canarias con el significado de «lápiz de color», y en Cuba, Méjico, Nicaragua y Santo Domingo con el de «lápiz para dibujar». Cristóbal Corrales y Dolores Corbella, Diccionario sobre las coincidencias léxicas entre el español de Canarias y el español de América (Santa Cruz de Tenerife: Cabildo Insular de Tenerife, 1994), 74.

${ }_{27}$ Bases del concurso, diario La Tarde (Santa Cruz de Tenerife), 28 de marzo y 27 de abril de 1944, 4 en ambos números.

${ }^{28}$ Gómez García, «Adoctrinando el futuro...», 143.
} 
emisión de otros de producción propia que, sin dejar de ser tributarios de tales afanes, dejaban más margen de esparcimiento a los pequeños. Esta doble oferta cesó a raíz de la debacle de las tropas alemanas en Stalingrado a inicios de 1943 y el subsiguiente viraje aliadófilo del franquismo, cuando los golpistas empezaron a recoger velas y a desmontar la infraestructura suplementaria de la emisora tinerfeña hasta dejarla, al término de la II Guerra Mundial, en la originaria estación local de baja potencia. ${ }^{29}$ A partir de entonces, las retransmisiones de la señal de Radio Nacional de España se redujeron a los «Diarios hablados» y a los actos más relevantes del gobierno franquista, lo que unido a la lejanía de Madrid y a la autonomía de Radio Club Tenerife al ser una emisora privada ajena a la SER, se encargaron de que la programación infantil, ahora toda de producción interna, relajara considerablemente el componente propagandístico.

Junto al inferior afán de adoctrinamiento, salvo en las efemérides históricas y religiosas exaltadas por el franquismo, cuyos actos conmemorativos corrían a cargo del Frente de Juventudes, el otro rasgo más característico de la programación infantil de Radio Club Tenerife, y de los capítulos restantes, siguió siendo el elitismo. El reducido alcance de la señal, la limitada extensión del tendido eléctrico y los escasos aparatos receptores que había en el archipiélago, hacían de la radio, por más que las audiciones fueran colectivas, un medio inalcanzable para buena parte de la población isleña. ${ }^{30}$

\section{LA DISTENSIÓN DE LA PROGRAMACIÓN EN EL PRIMER FRANQUISMO, 1945-1955}

El principal hito de los espacios infantiles de la radiodifusión franquista en la autarquía fue el cese definitivo de «Ondas animadas», que Radio Nacional de España había dejado de emitir en 1939 para, luego, reaparecer con carácter local en Barcelona, y la irrupción de «La onda mágica» desde el día de la Hispanidad de 1947, tras atenuar la asfixiante orientación propagandística que hasta entonces había impuesto el Frente de Juventudes. Diseñado en cumplimiento de la orden de 18 de marzo

\footnotetext{
29 Yanes Mesa, «La propaganda radiofònica de l’Espanya nacional...», 101-116.

30 Joaquín Carreras Navarro, Vida cotidiana en Tegueste a través de sus gentes durante la segunda mitad del siglo XX: una aproximación etnográfica (Tenerife: Ayuntamiento de Tegueste, 2014), 117-166.
} 
de 1946, que disponía la organización de actividades «atractivas», incluyendo «programas de radio y emisoras infantiles» en las escuelas, ${ }^{31}$ para captar la audiencia que no había sabido ganarse la propuesta anterior, en sus contenidos cedió mucho el burdo adoctrinamiento en beneficio del entretenimiento y la diversión. Los protagonistas eran una serie de hadas, magos y personajes bonachones que organizaban concursos, festivales y otros eventos, evidentemente con temáticas guiadas por la escala de valores que la dictadura estaba empeñada en sembrar en la sociedad española. Permaneciendo en antena hasta 1956, el formato sirvió de referencia a los programas del género puestos en antena por las emisoras locales en los años centrales del franquismo, al calor del afán de homogeneidad, de copia y de escasa creatividad reinante en toda dictadura.

El primer vástago de «La onda mágica» en el archipiélago fue «El Hada Azul y sus amiguitos», espacio conducido por la futura locutora del Centro Emisor del Atlántico de Radio Nacional de España Montserrat Martínez, que sustituyó al que llevaba Juan Antonio Torres Romero cuando este, como tantos otros isleños, emigró para Venezuela. Al igual que ocurriera en las emisoras peninsulares y, luego, en Televisión Española, ${ }^{32}$ la propuesta conllevó la organización de un «Club infantil» para fidelizar la audiencia, al que se incorporaron como socios los niños y niñas participantes o, simplemente, oyentes. A finales de la década, el personaje central, El Hada Azul, había dado paso a otro no menos entrañable, El Tío Pepote, a quien le dio voz el escenógrafo Eloy Díaz de la Barreda, el director del grupo de teatro de la emisora. Por entonces, el programa salía al aire con el patrocinio comercial de una fábrica local de caramelos, Yumbo, siguiendo también pautas que estaban en boga en las emisoras españolas, caso de la catalana Ràdio Vilanova. ${ }^{33}$

Con el ropaje de la bonhomía, Eloy Díaz de la Barreda presentaba los concursos y actuaciones infantiles que, ahora, concluían con el lanzamiento de caramelos desde el escenario hacia las butacas en las que estaban los pequeños espectadores. Para realzar la recepción de las golo-

\footnotetext{
31 Gómez García, «Adoctrinando el futuro...», 147.

32 María Antonia Paz Rebollo y Lizette Martínez Valerio, «La primera conformación de una audiencia infantil y juvenil para la televisión en España (1958-1968)», Estudios sobre el Mensaje Periodístico, 20 (2014), 43-58.

33 Espinosa Mirabet y Borrero, «Los programas infantiles de radio en Cataluña...», 56.
} 
sinas, el momento más esperado por los presentes en una época de tantas privaciones para la infancia, se hacía sonar una estridente bocina en el recinto. A los niños y niñas de las élites sociales que podían permitirse el lujo de escuchar el programa en sus hogares, los padres solían colocar disimuladamente los caramelos detrás del aparato receptor mientras estaban absortos en la audición para, al salir al aire el estruendoso pitido final, decirles que comprobasen si los duendes de las ondas se habían acordado de ellos. ${ }^{34}$ Entre los precoces artistas que más solían participar en estos años se contaron la futura soprano tinerfeña María Orán, ${ }^{35}$ quien hiciera por entonces sus primeros pinitos en el bel canto, y el que habría de destacar como controlador de sonido en Radio Juventud de Canarias y, luego, en el Centro Emisor del Atlántico de Radio Nacional de España, Diego García Soto.

\section{LA DIVERSIFICACIÓN DE LA OFERTA TRAS LA PUESTA EN MARCHA DE LAS EMISORAS INSTITUCIONALES EN LA PROVINCIA}

Con la inauguración de Radio Juventud de Canarias a finales de 1955, los niños y niñas tuvieron a su disposición, todos los días a las 13:00 horas, «Ballenato, audición infantil», un espacio de producción interna centrado en un cuento y canciones infantiles con dedicatoria cuyo formato estaba en boga en todo el país. Como estación que era de la $\mathrm{Ca}$ dena Azul de Radiodifusión (CAR) dirigida al segmento más joven de la población, también se retransmitieron programas juveniles en conexión con Madrid, caso de «La Ballena alegre», que se emitía a las 19:00 horas de la tarde, en el que tenían cabida un serial, anécdotas, curiosidades y concursos. ${ }^{36}$ Tanto la tardía implantación de las ondas hertzianas en el archipiélago como las carencias de la época están ilustradas en los escasos sesenta participantes de la isla de Tenerife que se inscribieron en el

\footnotetext{
${ }^{34}$ Agradecemos estos detalles, de los que no ha quedado huella documental, a uno de los protagonistas infantiles, Diego García Soto, quien entrara luego como técnico en plantilla de Radio Nacional de España.

35 María Teresa (Mayte) Méndez, «María Orán: el amor por la música creo que nació conmigo», diario La Opinión de Tenerife (Santa Cruz de Tenerife), 2 de abril de 2008, URL: www.laopinion.es, consultado el 13 de marzo de 2014.

36 Julio Antonio Yanes Mesa, Las ondas juveniles del franquismo. "Radio Juventud de Canarias», 19551978 (Santa Cruz de Tenerife: Baile del Sol, 2009), 189-190.
} 
concurso más atractivo de estos años, el titulado "Marisol invita», organizado por la $C A R$ en la primavera de 1962, mientras «los residentes en las islas menores [...] al tener que trasladarse por su cuenta a la capital de la provincia [...] han tenido que desistir a tomar parte en él». El premio consistía, nada menos que, en viajar a Madrid para participar, la pareja infantil seleccionada en cada provincia, en una serie de «agasajos, visitas, excursiones, funciones de cine y de teatro, y otras atracciones» en calidad de «huéspedes de Marisol». ${ }^{37}$

Las otras tres emisoras institucionales que funcionaron en las Canarias Occidentales durante el franquismo iniciaron simultáneamente su andadura un lustro después que la estación-escuela de la $C A R$, a mediados de 1960, en coincidencia con los inicios del boom turístico. Dos de ellas, La Voz del Valle y Radio Popular de Güímar, fueron montadas en las localidades más pujantes de las vertientes norte y sur de Tenerife antes del desarrollo del turismo, la primera en La Orotava por el Sindicato Vertical y la segunda en Güímar por el Obispado con la generosa aportación del vecindario. Para la tercera, $\mathrm{La}$ Voz de la isla de La Palma, ${ }^{38}$ que también pertenecía a la Cadena de Emisoras Sindicales, se eligió como sede la ciudad de Santa Cruz de La Palma, la capital de la isla «menor» más próspera de la época. La condición periférica y artesanal de estas estaciones emplazadas en el interior de la provincia, propició que en la programación infantil y juvenil de producción propia el adoctrinamiento en los valores del régimen se redujera, prácticamente, a los hitos y efemérides que celebraba el franquismo, entre los que descolló la parafernalia montada a propósito de los mal llamados « 25 años de paz».

El espacio infantil por excelencia de las tres emisoras respondía al formato introducido por Radio Juventud de Canarias a mediados de la década de los cincuenta, el cual estaba extendido desde hacía años por toda España, aunque con productos más modestos por las mayores limitaciones técnicas y de personal. Así, con periodicidades y títulos diversos, todas ellas pusieron en antena al mediodía, cuando los niños y niñas regresaban a sus casas para almorzar tras la jornada escolar matutina,

\footnotetext{
${ }^{37}$ Nota de la redacción, diario La Tarde (Santa Cruz de Tenerife), 31 de marzo de 1962, 7.

38 Julio Antonio Yanes Mesa y Edmundo Hernández Cabrera, «La Voz de la Isla de La Palma», 19601978. La radiodifusión del sistema comunicativo más singular de Canarias en el franquismo (La Palma: Ediciones Alternativas, 2011), 33-44.
} 
un cuento de unos quince minutos de duración y, como complemento, algunos discos de canciones infantiles con dedicatorias. En un principio, el espacio se producía en las propias emisoras, bien en directo o mediante la previa grabación al cierre de la estación, cuando el fluido eléctrico tenía la suficiente estabilidad para ello, en base a una voz en off y la recreación de los pasajes más significativos de cada relato por algunos de los actores aficionados que hacían el teatro leído. Luego, desde que llegaron las ofertas editoriales de las casas peninsulares, se adquirieron bloques de cuentos grabados, bien en cinta o en discos, que ya se emitían a diario siguiendo, normalmente, un turno.

En la emisora más desconectada de la capital provincial al estar ubicada fuera de Tenerife, La Voz de la Isla de La Palma, junto al espacio del cuento se consolidó otro infantil que, conjugando la diversión y la educación, se inspiró en la ya desaparecida «La onda mágica» de Radio Nacional de España. Con el reclamo del "Club Niñolandia», en el que se inscribieron los participantes y oyentes, y bajo el lema «Educar a los niños es evitar castigarlos cuando sean mayores" ${ }^{39}$ se diseñó un evento cara al público que todos los domingos, a la salida de la misa de las 12:00 horas, se celebraba en el pequeño recinto conocido como el Teatro Chico en presencia de los escolares con sus maestros. Los conductores iniciales fueron el locutor Miguel Lázaro Rodríguez (Mago Bonachón), quien entraría en Radio Club Tenerife en 1968, y su compañera en tareas radiofónicas Pilar Rey (Hada Maravilla), la cual empezó por entonces a hacer gala de las grandes dotes interpretativas que habrían de hacer del teatro su profesión. ${ }^{40}$ De inmediato, la loable iniciativa se ganó el respaldo de las instituciones insulares, en forma de apoyo logístico, y de las casas comerciales de la isla, estas costeando el reparto de «bolsitas de caramelos» ${ }^{41} \mathrm{y}$ obsequios similares en las fechas señaladas, así como con la contratación de anuncios publicitarios que generaban buenos ingresos para la emisora.

\footnotetext{
${ }^{39}$ Félix G. Curbelo, entrevista a Miguel Rodríguez (El Mago Bonachón), Diario de Avisos de Santa Cruz de La Palma, 21 de junio de 1965, 1.

40 Pilar Rey, tras contraer matrimonio con el también locutor radiofónico Antonio Abdo, concentró con éste toda su actividad posterior en el arte escénico, la recitación y, luego, la dirección de la Escuela municipal de teatro de Santa Cruz de La Palma desde su fundación, en 1981, hasta la actualidad, cosechando ambos varios galardones estatales. URL: escuelamunicipaldeteatropilarrey.bogspot.com, consultado el 25 de marzo de 2014.

${ }^{41}$ Félix G. Curbelo, «Los festivales de Niñolandia. Comentarios y opiniones sobre los mismos», Diario de Avisos de Santa Cruz de La Palma, 28 de enero de 1966, 3.
} 
Conforme avanzaron los años sesenta, «Club Niñolandia» incrementó cada vez más sus niveles de audiencia, tanto en La Palma como en La Gomera y el noroeste de Tenerife, las zonas a las que llegaba la señal de la estación palmera con cierta nitidez. Cuando la ocasión lo requería, el evento se celebraba en recintos más amplios para poder acoger a todo el público interesado en presenciar en directo las actuaciones de los precoces artistas, caso del Teatro-circo Marte o la plaza de Santo Domingo en la capital palmera. ${ }^{42}$ Causa y consecuencia de tan excelente acogida fueron los números cada vez más elaborados que se fueron introduciendo, caso del concurso «Estadio cultural», en el que los niños y niñas respondían en plan futbolístico a una serie de preguntas culturales que, consideradas como "pases del balón», debían «golpear» con las respuestas para, si acertaban, marcar el «gol» correspondiente, con el acicate de optar a una serie de premios que ofrecían el Ayuntamiento, ${ }^{43}$ las casas comerciales o la delegación insular del Frente de Juventudes. A finales de la década, para atender las demandas de la población infantil ajena a la capital insular interesada en participar en el evento, el programa se llevó a cabo en varias localidades del interior de la isla, desde donde se retransmitía vía telefónica. ${ }^{44}$

Sin duda alguna, un acicate para los conductores de tales espacios era la mayor libertad que tenían al amparo de la inocencia de su audiencia y la banalidad de los temas tratados, lo que en estas emisiones introdujo una frescura que estaba ausente en la programación más convencional. De ello dejó constancia la locutora Rosabel Rodríguez al reconocer que en los eventos infantiles, en contraposición a los restantes, «hablamos de una manera familiar, espontánea, improvisamos». ${ }^{45} \mathrm{Si}$ a ello añadimos el valor educativo del espacio en una época en la que primaban los métodos pedagógicos autoritarios y poco participativos, los altos índices de audiencia y el apoyo unánime de la ciudadanía, debemos convenir que

\footnotetext{
42 Peype, «Entre los niños. Grandioso éxito del festival Club Niñolandia», Diario de Avisos de Santa Cruz de La Palma, 21 de junio de 1965, 1; y 2 de septiembre de 1966, 6.

${ }^{43}$ Gabriel Gómez Forns (director de La Voz de la Isla de La Palma), 16 de diciembre de 1965, carta dirigida al Ayuntamiento de Santa Cruz de La Palma en solicitud de un trofeo para el concurso deportivo «Estadio cultural», dirigido a los escolares, dentro del programa «Club Niñolandia». Caja 1457, carpeta 20, Archivo Municipal de Santa Cruz de La Palma.

${ }^{44}$ Octavio Santos, «Crónica de Fuencaliente. Nos visitó el Club Niñolandia», Diario de Avisos de Santa Cruz de La Palma, 26 de julio de 1969.

${ }_{45}$ Félix G. Curbelo, «Los festivales de Niñolandia. Comentarios y opiniones sobre los mismos», Diario de Avisos de Santa Cruz de La Palma, 28 de enero de 1966, 3.
} 
«Club Niñolandia» fue una de las creaciones más notables de la radiodifusión canaria en el franquismo.

\section{LA SINGULARIDAD DE LOS PROGRAMAS ESPECÍFICAMENTE EDUCATIVOS}

Desde los años centrales del franquismo, todas las emisoras instituciones de la provincia, al igual que del resto del Estado y Radio Nacional de España, pusieron en antena los espacios educativos que promoviera el Ministerio de Educación Nacional con el asesoramiento del Centro de Orientación y Documentación Didáctica de Enseñanza Primaria y la Comisaría de Extensión Cultural. Paliar el problema de las bolsas de niños y niñas sin escolarizar fueron los objetivos de tales espacios, para cuya consecución se pusieron a disposición de todas las estaciones los cursos grabados en cintas magnetofónicas por los profesores, locutores, actores y técnicos de sonido movilizados a tal fin. Junto a estos programas producidos en Madrid que se intercalaban y, a menudo, se confundían con los propagandísticos del régimen, sobre todo, cada vez que llegaba el momento de estudiar los acontecimientos históricos o religiosos reivindicados como propios por el franquismo, las emisoras canarias emitieron otros de producción interna, alguno de los cuales con estrategias pedagógicas avanzadas para una época marcada por el dogmatismo y la apología del franquismo. Al igual que sucediera en el capítulo del entretenimiento, las propuestas más interesantes aparecieron en las emisoras más modestas y periféricas de la provincia.

En el caso de La Voz de la Isla de La Palma, en la primera mitad de los años sesenta, se emitía un curso de producción propia sobre un tema tan aséptico como el francés en el cuarto de hora previo, de 19:00 a 19:15 horas, ${ }^{46}$ al bachillerato radiofónico que venía grabado de Madrid, por lo que la parrilla de la programación de la época contenía una hora diaria, de 19:00 a 20:00 horas, dedicada específicamente a la enseñanza. La otra estación sindical, $\mathrm{La} \mathrm{Voz} \mathrm{del} \mathrm{Valle,}{ }^{47}$ ofrecía el curso preparatorio para la

\footnotetext{
46 Yanes Mesa y Hernández Cabrera, "La Voz de la Isla de La Palma», 1960-1978, 147-148.

47 Julio Antonio Yanes Mesa y Rodrigo Fidel Rodríguez Borges: La radiodifusión sindical del franquismo. "La Voz del Valle» en las Islas Canarias, 1960-1965 (Santa Cruz de Tenerife: Ayuntamiento de La Orotava, Cabildo de Tenerife y Dirección General del Libro, Archivos y Bibliotecas del Gobierno de Canarias, 2007), 153-166.
} 
reválida de cuarto de bachiller a iniciativa del jefe de programación, el sacerdote José Siverio, quien encargó la parte de «Ciencias», como se decía en la época, a un licenciado en Químicas y la de «Letras» a dos profesoras de un instituto laboral de la zona. Tras captar a una treintena de estudiantes a un canon por matrícula suficiente como para cubrir los gastos del material didáctico, los profesores desarrollaron su labor auxiliados de unas fichas elaboradas por ellos mismos y reproducidas en una multicopista artesanal que, previamente, habían repartido al alumnado. La metodología, similar a la que pondría en práctica Radio Ecca de Las Palmas a los pocos años, consistía en la realización de los ejercicios siguiendo las orientaciones oportunas, la devolución de las fichas cumplimentadas a la emisora y la corrección de cada una de ellas por los profesores delante del micrófono, quienes se dirigían a cada alumno dando unas explicaciones específicas que también eran de utilidad para los restantes. ${ }^{48}$ En contraposición a los espacios grabados en cinta del Ministerio de Educación, pues, se trataba de una enseñanza personalizada y, por lo tanto, antagónica a la practicada en los programas del género que estaban en boga por entonces en la España franquista.

Pero, sin duda alguna, los espacios más innovadores que, en los años centrales del franquismo, salieron al aire en las Canarias Occidentales a través de este «medio unisensorial ${ }^{49}$ fueron los emitidos por la emisora más modesta de la provincia, Radio Popular de Güímar. El artífice de la iniciativa fue un joven maestro nacional vasco destinado en el municipio, Javier Apraiz de Elorza, quien hiciera gala de las inquietudes que, con el paso de los años, lo convertirían en un acreditado especialista de la educación de los niños y niñas con necesidades especiales. ${ }^{50}$ Pues bien, tras organizar un «Club de Amigos Infantil» a imagen y semejanza de los

\footnotetext{
${ }^{48}$ Estos detalles que, como tantos otros, no dejaron huella en la documentación legada por la emisora, nos los ofreció oralmente el propio sacerdote José Siverio Pérez.

${ }^{49}$ Irene Melgarejo Moreno y María del Mar Rodríguez Rosell, «La radio como recurso didáctico en el aula de infantil y primaria: los Podcast y su naturaleza educativa», Tendencias Pedagógicas, 21 (2013), 31.

50 Javier Apraiz de Elorza (07/12/1936) inició por entonces sus estudios universitarios en la Universidad de La Laguna y, tras doctorarse en Filosofía y Ciencias de la Educación por la Universidad de Salamanca, abandonó la docencia en los niveles básicos para trabajar en el Servicio de Educación Especial del Departamento de Educación, Universidades e Investigación del Gobierno del País Vasco. La educación del alumnado con altas capacidades, coord. Javier Apraiz de Elorza, (Vitoria-Gasteiz: Departamento de Educación, Universidades e Investigación del Gobierno Vasco, 1995), consultado el 24 de febrero de 2014. URL: www.euskadi.eus/.../110005c_Doc_altas_capacidades_c.pdf.
} 
que todavía pululaban en el medio, el vocacional docente puso en antena una serie de espacios educativos cuyo denominador común era una metodología activa que chocaba frontalmente contra el memorismo y la pasividad que, por entonces, primaban en el aprendizaje. Para mayor contraste con el autoritarismo y la adustez de los maestros de la época, Apraiz de Elorza impartía sus enseñanzas bajo el ropaje de un personaje de ficción, Don Séneca, cuya autoridad cimentaba en el liderazgo y la vocación científica, no en la intimidación, al tiempo que incentivaba la participación de los escolares con la intercalación de juegos de magia y la acomodación de la modulación de la voz a cada contenido. ${ }^{51}$

Con tales ingredientes, Radio Popular de Güímar invitaba todos los lunes a su audiencia infantil a investigar y a buscar información por su cuenta a la salida de clase para responder a un listado de cuestiones y elaborar una serie trabajos sobre los temas tratados de manera convencional en el aula. Con el propósito de abrir la actividad a todas las edades, los problemas se formulaban con tres grados de dificultad tomando como referencia las ediciones de la célebre enciclopedia Álvarez y los libros de textos de las escuelas de la época, para así garantizar que los retos planteados estuvieran acordes a los niveles formativos. Lanzado el desafío al aire, los participantes hacían llegar sus respuestas a la emisora en días sucesivos para, cuando llegaba el sábado, escuchar las correcciones y calificaciones oportunas en sus hogares a través de los aparatos receptores. En cada emisión, los peor calificados eran eliminados hasta quedar un número reducido de concursantes, los cuales dirimían entre ellos el pase a la final en el estudio de la emisora, colocados en torno al micrófono, en donde respondían en directo al cuestionario formulado. Como colofón, los finalistas eran citados en el cine de la localidad tras la misa dominical de la mañana, a la que iban todos los niños con sus maestros, en donde ellos mismos se formularan entre sí las preguntas eliminatorias extraídas de la enciclopedia Álvarez hasta quedar los ganadores de las distintas modalidades.

Con el mismo formato, Javier Apraiz de Elorza tuvo en antena otros espacios centrados en materias determinadas, como el dibujo, o en objetivos educativos muy concretos, como el fomento de la limpieza del municipio. En el primer caso, los trabajos se seleccionaban cada fin de

\footnotetext{
51 Julio Antonio Yanes Mesa, Los orígenes de la COPE en Canarias. «Radio Popular de Güímar», 19601969 (Santa Cruz de Tenerife: Baile del Sol, 2007), 153-161.
} 
semana y se exponían en la sala de recepción de la emisora para, tras el oportuno proceso eliminatorio, celebrar también la final una mañana de domingo en el cine local, tras la misa de las 12:00 horas, desde donde tales eventos eran radiados en directo vía telefónica. Todas estas iniciativas conformaron una atrayente propuesta para muchos niños y niñas en una época en la que, tras la jornada escolar, y cuando aún no emitía la televisión, las actividades de ocio escaseaban sobremanera, lo que hizo a muchos de ellos enfrascarse en actividades de aprendizaje autónomas con metodologías activas que, según recuerda alguno de los que luego se dedicó a la docencia e investigación universitarias,,$^{52}$ despertó en ellos una motivación que no tenían por el estudio.

A partir de 1964, con la puesta en marcha de Televisión Española en Canarias, en febrero, y del Centro Emisor del Atlántico de Radio Nacional de España, en julio, el contexto comunicativo insular aceleró su integración en el estatal. Consecuencia de ello fue el progresivo repliegue de los espacios infantiles y juveniles de producción interna, como ocurriera en toda la parrilla de la programación, al no poder competir con los más sofisticados que se emitían en conexión con Madrid. Luego, con la inmediata entrada en vigor del Plan Transitorio de Radiodifusión en Ondas Medias, ${ }^{53}$ las emisoras sobrevivientes desplazaron los programas educativos a la recién montada frecuencia modulada, cuya penetración social era bajísima por los escasos aparatos receptores que por entonces estaban dotados para captar tal tipo de señal. Paralelamente, las ondas hertzianas entraban en una profunda crisis al drenar al pujante medio audiovisual la audiencia del prime time nocturno y, con ella, el grueso del pastel publicitario hasta entonces monopolizado. ${ }^{54}$ Pero al igual que los procesos anteriores, este se dejó sentir de manera tan desacompasada en el sector que La Voz de la Isla de La Palma, la emisora más periférica de la provincia, mantuvo el respaldo social a sus programas infantiles y juveniles de producción propia hasta finales del franquismo.

\footnotetext{
${ }^{52}$ Nos referimos a Pedro González Leandro (20/03/1950), profesor titular del Departamento de Psicología Clínica, Psicobiología y Metodología de la Universidad de La Laguna, cuya área de conocimiento es Personalidad, Evaluación y Tratamientos Psicológicos. URL: https://pereva.webs.ull.es/ profesorado.htm, consultado el 14 de julio de 2015.

${ }_{53}$ Eduardo Gorostiaga Alonso-Villalobos, La radiotelevisión en España (Aspectos jurídicos y derecho positivo) (Pamplona: Universidad de Navarra, 1976), 161-458.

${ }^{54}$ Guillermo Aguado Monjas, «La Televisión Pública en Canarias» (Tesis doctoral, Universidad Complutense de Madrid ,1992), 205.
} 


\section{CONCLUSIONES}

El análisis de los programas infantiles y juveniles de la radiodifusión canario-occidental durante el franquismo, no sólo nos ha confirmado la irrelevancia de la carga propagandística de la producción interna en relación a la externa, bien grabada en cintas en Madrid o elaborada por la militancia franquista en las islas, sino que, además, lo ha hecho desvelando varios detalles dignos de consideración. En primer lugar, debemos destacar que tal diferenciación ya era claramente visible a la finalización de la guerra civil, cuando Radio Club Tenerife empezó a emitir, al margen de los espacios foráneos marcados por los afanes proselitistas del naciente régimen, otros de producción propia que daban cancha al entretenimiento y la diversión. El polifacético locutor Juan Antonio Torres Romero, bajo el ropaje de personajes de ficción como el Hombre Bueno, el Príncipe Infantil o El Abuelito, fue el conductor de tales programas en los años más duros de la autarquía franquista. Junto a estos programas orientados al entretenimiento, estuvieron por entonces en antena otros culturales en la acepción más excelsa del término, en cuyo desarrollo los niños y niñas eran tratados como adultos en potencia, y una serie de concursos literarios y artísticos que culminaban con exposiciones abiertas al público de las obras más destacadas de los pequeños artistas. Todos esos espacios, aunque no pudieron sustraerse de la escala de valores vigentes de la época, nacieron con propósitos esencialmente educativos a iniciativa del personal de la única emisora que, por entonces, emitía en la provincia occidental del archipiélago.

En los años centrales del franquismo, el espacio que bajo el rubro «La onda mágica» puso en antena Radio Nacional de España el día de la Hispanidad de 1947, con la estrategia de crear un «club infantil» para fidelizar la audiencia, sirvió de referencia para remozar la producción de la época. La otra fuente de inspiración llegó con la puesta en marcha, a finales de 1955, de Radio Juventud de Canarias, de la Cadena Azul de Radiodifusión $(C A R)$, cuyo espacio de producción propia «Ballenato audición infantil», centrado en un cuento y canciones infantiles con dedicatorias, trajo al archipiélago un formato que estaba en boga en todo el país. Aunque por entonces el número de aparatos receptores instalados en el archipiélago había aumentado en relación a los escasos tres millares que había a finales de la guerra civil y el alcance de la señal de la nueva emisora rebasaba de largo el de Radio Club Tenerife, el elitismo seguía siendo el 
rasgo más característico del medio, tanto por los bajos niveles de vida de las clases populares, que era como decir el grueso de la población, como por la reducción del tendido eléctrico instalado en el territorio insular.

Con los inicios del boom turístico y la paralela inauguración, a mediados de 1960, de La Voz del Valle de La Orotava, Radio Popular de Güímar y La Voz de la Isla de La Palma, las ondas hertzianas isleñas ampliaron su área de cobertura y, con las subsiguientes mejoras socioeconómicas y la llegada de los transistores de pilas, se hicieron cada vez más accesibles a la infancia de las clases populares. Fue en ese contexto de bonanza económica en el que la radiodifusión isleña puso en antena, en el clima favorecedor de la creciente escolarización de la población infantil y juvenil, los espacios educativos más relevantes de la época, todos producidos artesanalmente en las emisoras más periféricas y, quizás por ello, más permeables a la creatividad y la heterodoxia. Así, mientras La Voz de la Isla de La Palma emitía, con un marcado tono lúdico y participativo, «Club Niñolandia» bajo el lema «Educar a los niños es evitar castigarlos cuando sean mayores», Radio Popular de Güímar producía, a iniciativa del joven maestro vasco de enseñanza primaria destinado en el municipio, Javier Apraiz de Elorza, una serie de programas educativos cuyos ejes fundamentales eran un aprendizaje activo, creativo y, dentro de un ambiente festivo, personalizado, el cual brillaba por su ausencia en los centros educativos de la época.

La investigación también nos ha permitido confirmar que el proselitismo ideológico dirigido específicamente a la infancia por la radiodifusión isleña se circunscribió a los espacios de producción externa que venían grabados de Madrid y a los extraordinarios que, con instrucciones muy precisas, elaboraba el reducido círculo del Frente de Juventudes isleño en conmemoración de los hitos históricos asumidos como propios por el ideario franquista. Ese desinterés en propagar la ideología del régimen por el personal de las emisoras guarda coherencia, tal y como ha dejado claro en un alto grado de coincidencia toda la historiografía ocupada del tema, ${ }^{55}$ con la reducidísima implantación de Falange y el unánime rechazo

\footnotetext{
55 Ilustrativas de tal realidad fueron las palabras del gobernador civil ,Vicente Sergio Orbaneja, a finales de la guerra civil: «el partido (Falange) nació aquí (en Canarias) el mismo día del Alzamiento Nacional, pues antes tenía solo unos catorce afiliados»; al igual que las de uno de sus sucesores, Luis Rosón Pérez, quien a inicios de los años cincuenta lamentara «la falta de vocación política que era pronunciada en esta provincia». En el mismo sentido apunta la principal aspiración de la «clase
} 
de las tesis autárquicas del régimen en el archipiélago. El marcado hecho diferencial isleño que, dentro del contexto estatal, ha generado históricamente la tardía incorporación al mundo occidental, la lejanía de Madrid, las escasas relaciones con la península, la tradicional apertura económica al exterior y, en coherencia con todo ello, el pragmatismo y el moderantismo de la idiosincrasia insular, hacen explicables tal singularidad. Esa tendencia incluso se dio dentro del archipiélago, toda vez que las emisoras isleñas más periféricas fueron las que dieron cancha a las metodologías más novedosas en los programas educativos, y en donde la programación infantil de producción propia resistió mucho mejor la dura competencia que, a partir de 1964, ejerció Televisión Española en Canarias.

\section{Nota sobre el autor:}

Julio Antonio Yanes Mesa (Güímar, Islas Canarias, 1951) es doctor en Historia (1991) y en Periodismo (2001) por la Universidad de La Laguna, y profesor titular de Historia de la Comunicación de la Facultad de Ciencias Políticas, Sociales y de la Comunicación de dicha universidad. Su línea de investigación ha partido, desde el punto de vista geográfico, de la isla de Tenerife, desde el cronológico, de los años de entreguerras (1914-1939), y desde el documental, de las fuentes hemerográficas isleñas; ámbitos que, poco a poco, ha rebasado y diversificado dentro del marco de las Islas Canarias, conforme ha ido planteando y dando respuesta a los problemas surgidos en su labor investigadora. Bajo tales directrices, su producción historiográfica ha abordado, de manera complementaria e íntimamente relacionada entre sí, temas tan diversos como la emigración, la prensa, la radiodifusión o la vida cotidiana, en un proceso investigador cuyos hilos conductores han sido la comunicación social y, sobre bases exclusivamente empíricas, los problemas relacionados con la escritura de la Historia. Tiene reconocidos dos sexenios de investigación por la Comisión Nacional Evaluadora de la Actividad Investigadora (CNEAI). Página web: https://sites.google.com/site/julioyanesmesa/

\footnotetext{
dominante» isleña después de la etapa excepcional del Mando Económico: la recuperación de los puertos francos, hasta el extremo de convertir su consecución en el objetivo prioritario que, en 1953, se trazó el I Congreso provincial de FET y de las JONS, en abierta contradicción con las tesis autárquicas del ideario falangista (Aarón León Álvarez, La institucionalización del franquismo ..., 179, 393, 369 y 403 , respectivamente).
} 